PUPIL: International Journal of Teaching, Education and Learning

ISSN 2457-0648

Azzopardi E Azzopardi, 2022

Volume 5 Issue 3, pp. 99-111

Received: 22nd April 2021

Revised: 07th August, 28 th September 2021, 6 th January 2022

Accepted: 12 th January 2022

Date of Publication: 18 th January 2022

DOI-https://doi.org/10.20319/pijtel.2022.53.99111

This paper can be cited as: Azzopardi, M. E Azzopardi, C. (2022). Biology Essay Questions: Cognitive Level as Revealed by Bloom's Taxonomy. PUPIL: International Journal of Teaching, Education and Learning, 5(3), 99-111.

This work is licensed under the Creative Commons Attribution-Non Commercial 4.0 International License. To view a copy of this license, visit http://creativecommons.org/licenses/by-nc/4.0/ or send a letter to Creative Commons, PO Box 1866, Mountain View, CA 94042, USA.

\title{
BIOLOGY ESSAY QUESTIONS: COGNITIVE LEVEL AS REVEALED BY BLOOM'S TAXONOMY
}

\author{
Marthese Azzopardi \\ Senior Lecturer, PhD, Department of Biology, University of Malta Junior College, Msida, Malta \\ marthese.azzopardi@um.edu.mt \\ Carmel Azzopardi \\ Senior Lecturer, Department of Physics, University of Malta Junior College, Msida, Malta \\ carmel.g.azzopardi@um.edu.mt
}

\begin{abstract}
Examination questions indicate the cognitive level anticipated from students. Although essays have the potential to test higher cognitive skills, the extent of their effectiveness in assessing these is not clear. The objective of this study was to estimate how well Biology essay questions measure higher-order cognitive skills in a public post-secondary institution in Malta. The essay questions were classified into cognitive levels based on Bloom's Revised Taxonomy and categorized as those demanding lower-order thinking skills (LOTS) and higher-order thinking skills (HOTS). No essays from the Applying and Creating objectives were recorded. Except for one year, questions from at least three cognitive objectives were present in each examination paper. Results showed that questions from the Remembering cognitive objective predominated. Some topics comprised $100 \%$ LOTS but others were from three objectives. These results indicate
\end{abstract}


that paper setters attempt to design essay titles that belong to various cognitive objectives, but more attention should be dedicated to diversifying. The value of this study is that examiners have a database to choose a mixture of LOTS and HOTS in future examinations, rendering them more effective. The findings highlight the importance for examiners to use Bloom's Revised Taxonomy when constructing questions.

\section{Keywords}

Bloom's Revised Taxonomy, Biology, Lower-Order Thinking Skills, Higher-Order Thinking Skills, Cognitive Objectives

\section{Introduction}

Biology at the Advanced level is a requirement for various medically-oriented degrees at the University of Malta, such as Physiotherapy, Nursing, and Doctor of Medicine and Surgery. According to the latest Statistical Report (2020): Matriculation Certificate Examinations, out of 3310 registrations (pg. 12) for the September 2020 examination, 587 were biology candidates (pg. 29) of which 394 also sat for Chemistry(pg. 80). Students register for two subjects at the Advanced level that form four groups. From Group 4, which comprises Biology, Physics, Chemistry, Applied Mathematics, and Pure Mathematics, Biology was the subject with the highest number of registrations. Since the Statistical Report (2020): Matriculation Certificate Examinations states that the most popular subjects at the Advanced level were English (734 candidates) and Maltese (419 candidates) from Group 1 (pg. 20), it may be said that a substantial number of candidates (587) opted for Biology in Group 4. In the Maltese educational system, 1617-year-old students spend two years studying biology at the Advanced level in preparation for the National examination. Most of the biology students end up as professionals in the medical field, dealing closely with human lives. They often find themselves in situations that require immediate assessment of a problem and subsequent action. Critical thinking and cognitive abilities are still developing in adolescents (Nippold et al., 2020). Structural and connectivity changes in the brain at puberty or shortly thereafter, allow rapid cognitive growth. The National Biology syllabus refers to the examination of higher-order thinking skills, and thus students must be trained in answering such questions. The syllabus states that 'a minimum of $25 \%$ of the marks of the overall examination will be dedicated towards higher-order thinking skills' (MATSEC, 2019 pg. 5). Various authors, such as Supovitz (2009) argue that high-stakes assessment results 
in a watered-down syllabus, where students learn by memorizing rather than developing a deep level of understanding. Palmer \& Devitt (2007) believe that essays have the potential to test higher cognitive skills besides recall of knowledge, comprehension of information, and the students' power of expression, ability to organize thoughts and communicate them in writing. In this investigation, essays testing students after completing the first year of studies at a public institution were analyzed to determine their cognitive level. Kurdi (2015) describes essays as being open-ended if the students' response is unrestricted and closed-ended if it is restricted. Essays analyzed in this study were closed-ended because students were given a statement that required a response. An example of such an essay is: 'The cell surface membrane is an effective barrier between the cell and its surrounding environment. Discuss.' Bloom's Revised Taxonomy (Anderson et al., 2001) was employed as a yardstick to find how effective essay titles are as a summative test for biology at the Advanced level. Objectives fall under six categories in such taxonomy (Edussuriya et al., 2018);

1. Remembering (Recall data or information),

2. Understanding (Understand the meaning, translation, interpolation, and interpretation of instructions and problems),

3. Applying (Use a concept in a new situation),

4. Analyzing (Separate material or concepts into parts so that its organizational structure may be understood, distinguishes between facts and inferences),

5. Evaluating (Make judgments about the value of ideas or materials),

6. Creating (Build a structure or pattern from diverse elements, put parts together to form a whole, with emphasis on creating a new meaning or structure).

Details regarding the literature review about Bloom's Revised Taxonomy may be accessed from Azzopardi \& Azzopardi (2020; 2021).

\section{Research Issues}

The overall objective of this investigation was to establish at which cognitive level examination essay questions test 16-17-year-old students attending a state-funding institution in Malta. This type of question was chosen for analysis as essays can assess students over the whole range of cognitive abilities of the Advanced level syllabus. The main objectives of this study were: 
1. Classification of question types using Bloom's Revised Taxonomy of educational objectives-cognitive domain.

2. Determining the percentage of lower-order thinking skills (LOTS) and higher-order thinking skills (HOTS) essay questions.

3. Categorizing topics according to Bloom's Revised Taxonomy and as LOTS and HOTS.

The significance of the present research is in its reference to and reliance on Bloom's Revised Taxonomy, which has the potential to examine the merits and demerits of examinations. The findings can help paper-setters to compose questions with the appropriate proportion of lowand high-order cognitive levels.

\section{Methods}

Verbs in the biology examination essay titles were used to quantitatively examine the cognitive level of each question. Action verbs were classified into 6 levels of thinking followingBloom's Revised Taxonomy (Anderson et al., 2001). Details of how this was carried out are outlined below.

\subsection{The Examination}

The end-of-year biology Advanced Level examination, at the public institution under research consists of two papers, each being 3 hours long. Paper 1 (total marks: 100\%) is composed of compulsory short-answer questions. Paper 2 comprises a compulsory comprehension test (total marks: 25\%), a choice of two structured essays to choose one(total marks: 25\%), and a choice of four unstructured essays to answer two (total marks: 50\%). Students are allocated about 45 minutes to answer an unstructured question in Paper 2. Although this study focuses on the 40 unstructured essay-type questions extending over the period $2010-$ 2019, the cognitive level of the comprehension questions over the same period at the same public institution were investigated by Azzopardi \& Azzopardi (2020). A glimpse on the cognitive level of Paper 1 short questions was reported by Azzopardi \& Azzopardi (2021) as they comparedthe 2017 and 2018papersat the mentioned institution with those of the National examinations.

\subsection{Grouping the Questions According to Bloom's Revised Taxonomy}

The verb in each of the 40 essay titles was identified. However, a specific title was not automatically categorized into one of the six cognitive objectives based on Bloom's Revised 
Taxonomy (Anderson et al., 2001) as shown in Table 1. Each title was evaluated on the biology expertise of the authors before being placed into a specific cognitive category. For example, although the verb 'discuss' featured in two essays, they were placed in a different cognitive catgory.

'Despite the relatively restricted number of chemical elements found in living organisms, the molecules they form are structurally very diverse and complex. Discuss.' (Paper 2: May 2010) 'The development of a coelom was a major step in the evolution of the animal body plan. Discuss.' (Paper 2: June 2011)

From the two examples above, it is clear that a higher level of thinking was required to answer the May 2010 essay, compared to that in June 2011. The May 2010 essay presented students with a challenging novel situation and was categorized as Analyzing while that in June 2011 was remembering since it was a pure recall.

An Excel sheet was set up with a column comprising the six cognitive objectives and the rows, the essay numbers, and the corresponding topic. The category to which the verb belonged, was marked allowing totals and percentages to be computed for each category and topic. Essays were grouped into 12 topics as shown in Figure 4.The next step was clustering the questions into two broad levels of cognition: those requiring lower-order thinking skills (LOTS: Remembering, Understanding, Applying) and higher-order thinking skills (HOTS: Analyzing, Evaluating, Creating).The same was done for topics.

Table 1: Bloom's Revised Taxonomy of Educational Objectives

\begin{tabular}{|l|l|}
\hline \multicolumn{1}{|c|}{ Category } & \multicolumn{1}{c|}{ Key Verbs (keywords) } \\
\hline Remembering [low-order] & $\begin{array}{l}\text { List, Name, Recognize, State, Describe, Recall, Repeat, } \\
\text { Retrieve }\end{array}$ \\
\hline Understanding [low-order] & $\begin{array}{l}\text { Conclude, Define, Illustrate, Predict, Tell, Identify, } \\
\text { Summarize, Categorize, Classify, Discuss, Compare, } \\
\text { Contrast, Explain }\end{array}$ \\
\hline Applying [low-order] & Generalize, Infer, Show, Use \\
\hline Analyzing[high-order] & Distinguish, Select, Arrange, Organize, Outline \\
\hline Evaluating [high-order] & Assess, Justify, Critique, Judge \\
\hline Creating [high-order] & Design, Compose, Plan, Hypothesize, Revise \\
\hline
\end{tabular}

(Source: Anderson et al., 2001: Cognitive Domain with Associated Verbs) 


\section{Results \& Discussion}

Results are presented graphically in Figures 1-5 as percentages. To answer the three objectives of this research, the results are subdivided into three sections: Classifying question types according to Bloom's Revised Taxonomy, Determining the percentage of LOTS and HOTS essay questions, and Categorising topics according to Bloom's Revised Taxonomy and as LOTS and HOTS.

\subsection{Classifying Question Types According to Bloom's Revised Taxonomy}

Two observations can be made from the data collected over 10 years as shown in Figure 1. The first is that essay questions from the Remembering objective predominated. The following is a list of percentage of questions per cognitive objective when placed in descending order: Remembering (42.9\%), Analyzing (28.6\%), Understanding23.7\%, and Evaluating (4.8\%).This list indicates that the percentage of questions in the cognitive objectives Analyzing and Understanding is very similar. The second important observation that results from Figure 1 is that essay questions over the 10-year study period did not assess students over the whole range of cognitive abilities. The Applying and Creating objectives were lacking. The Applying objective involves solving problems to novel situations by applying acquired knowledge, facts, techniques, and rules differently.However, biology essays are not intended to test this objective at the level investigated. The same applies to the Creating objective that involves putting parts together to form a whole, with emphasis on creating a new meaning or structure. Examinations, where specific cognitive objectives were missing, have been reported in the literature. For example, Cullinane \& Liston (2016), found that the Creating and Evaluating objectives were missing from the Irish Leaving Certificate Biology examination papers between 1999-2008.

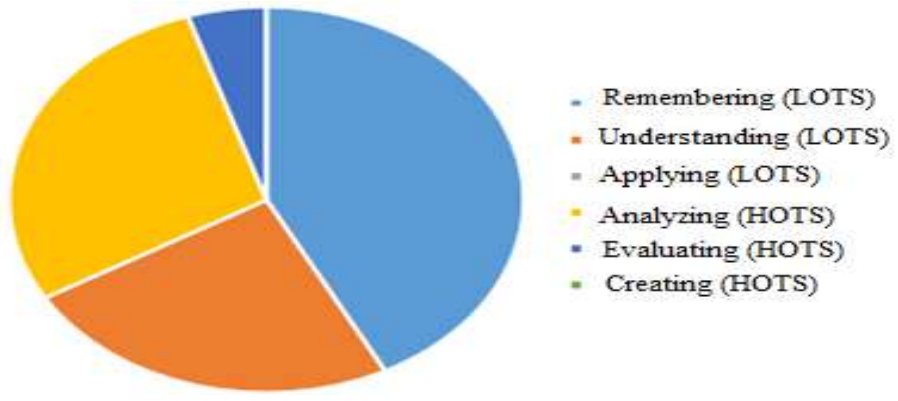

Figure 1: Percentage of Essay Questions Classified According to Bloom's Revised Taxonomy Over the Period 2010-2019 


\section{(Source: Author's Own Illustration)}

Research carried out by Azzopardi \& Azzopardi (2021) also revealed missing objectives in short questions (Paper 1) as well as comprehension test questions in Paper 2 (Azzopardi \&Azzopardi,2020) at the same institution where the present investigation acted as a source of data. The Analyzing objective was absent in 121 comprehension test questions (Azzopardi \& Azzopardi, 2020) over the same 10-year period as for the present study. Azzopardi \& Azzopardi (2021) discovered that the Creating objective was lacking in 2017 Paper 1 short questions in both the National (108 questions) and the same public institution (97 questions). However, it must be pointed out that the examination at the institution investigated, catered for the Creating objective in the 2018 Paper 1. Azzopardi \& Azzopardi (2021) reported that $4.1 \%$ of the 2018 Paper 1 questions were of the Creating objective. An example of a question (2018 Paper 1; Number $8 \mathrm{~b}$ ) where students are asked to design an experimental procedure is: 'Devise and describe an experimental procedure that investigates the effect of wind on the rate of transpiration. Use the setup you drew in part (a) and an electric fan in your procedure. Take readings every 30 seconds over a 3-minute period.' On the other hand, it must also be pointed out that the percentage of questions in the Creating objective (4.1\%) is still low compared to that of the Remembering objective (44.9\%) in the same paper.

Figure 2 shows that within a specific year, questions belonged to a minimum of two cognitive objectives (Remembering and Understanding) in 2018 and a maximum of four in 2017 (Remembering, Understanding, Analyzing, and evaluating).

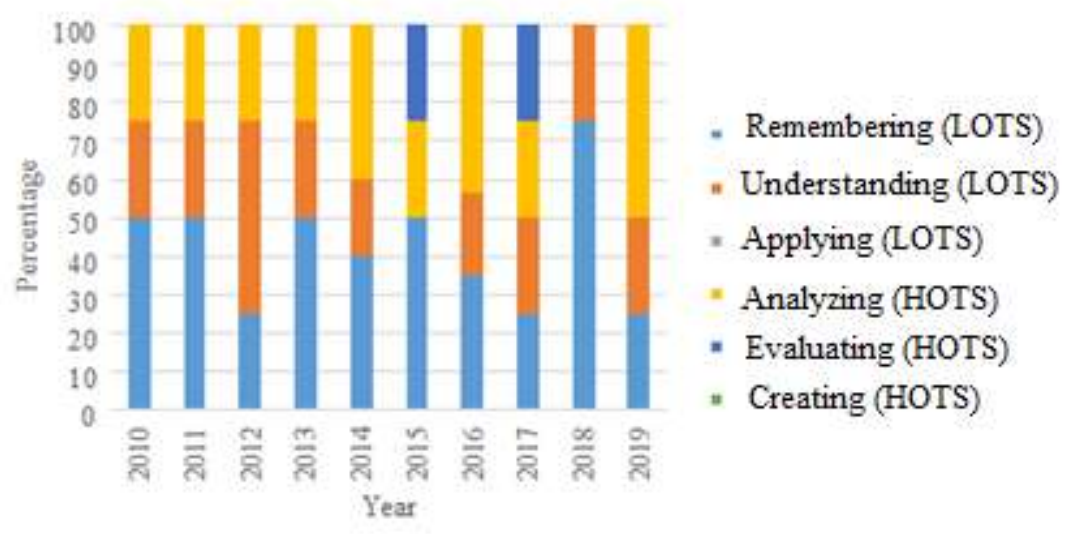

Figure 2: Yearly percentage of essay questions classified according to Bloom's Revised Taxonomy over the period 2010-2019 (Source: Author's Own Illustration) 
Essay questions from the Remembering objective ranged from 25 to $75 \%$ over the study period, reaching the highest percentage (75\%) in 2018. A comparable percentage (20.0 to 83.3\%) of Paper 2 comprehension questions was reported by Azzopardi \& Azzopardi (2020) over the period: 2010-2019. Azzopardi \& Azzopardi (2021) discovered that the majority (34.0\% in 2017 and $44.9 \%$ in 2018) of Paper 1 short questions belonged to the Remembering objective. Results in Figure 2 indicate that paper setters attempt to design essay titles that belong to various cognitive objectives, however, they were not always successful as in the case of 2018.

\subsection{Determining the Percentage of LOTS and HOTS Essay Questions}

Over the period 2010-2019, the majority of essay questions (67\%) tested LOTS. Figure 3 shows that the same applies when the yearly results are analyzed, especially in 2018, where $100 \%$ of the questions were LOTS. Results published by Azzopardi \& Azzopardi (2020) for Paper 2 comprehension test questions and short type questions in Paper 1 (Azzopardi \& Azzopardi, 2021), show that the majority are LOTS at this institution. Azzopardi \& Azzopardi (2020) reported that $91.6 \%$ of the comprehension test questions required LOTS over the same 10-year period and $85 \%$ of Paper 1 short-type of questions over two years (2017 and 2018) (Azzopardi \& Azzopardi, 2021).Mercieca (2014) studied the trends in Advanced-level Biology National examinations from 1998 to 2011 by recording the percentage of questions that were recall- or thought-based in each of the four papers. She reported a substantial amount of recallbased essay questions in the National papers but acknowledged that from 2000 onwards, although the essays were still more recall-based, more thought in the answers was needed. However, since she recorded the percentage of questions per paper and not the individual type of question, no comparison was possible. The National Syllabus does not state the percentage of HOTS expected in each of the four papers, but that they carry an overall $25 \%$ of the marks.

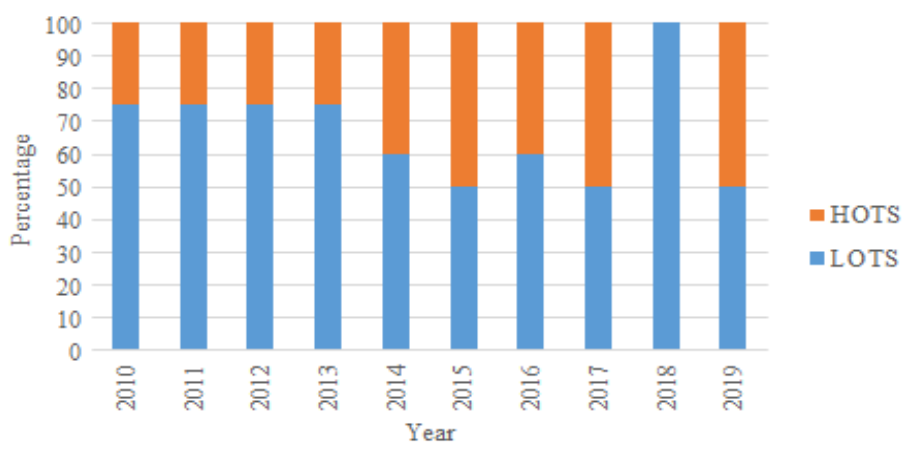

Figure 3: Yearly percentage of LOTS and HOTS essay questions over the period 2010-2019 


\section{(Source: Author's Own Illustration)}

Attention must be drawn to the method employed to categorize the questions. To categorize a specific question, both the wording as well as the context of the subject matter was taken into consideration as illustrated by the following example. Although a verb used in a question required HOTS, the question was listed as 'recall' if the same has been discussed in class and therefore requiring LOTS. Since one of the authors teaches biology at an Advanced level, she is knowledgeable regarding what is taught and thus could classify questions accordingly. This procedure has been encountered in the literature, such as in the study by Edussuriya et al. (2018) on Sri Lankan medical undergraduate modified essay questions. These authors also recorded a predominance of essay questions requiring LOTS and propose some reasons for this which is also applicable to this study. One reason is that questions requiring knowledge and comprehension could be evaluated more objectively compared to those requiring HOTS. This is especially true when assessing a large number of students. Knowledge-based questions eliminate subjectivity and impart fair assessment, leaving no possibility for the student's point of view on the subject with which the examiner may not agree. Another reason for including many LOTS questions is the examiners' "negative perception of students" English language ability. The majority of Maltese students struggle to write coherent sentences as English is their second language

\subsection{Grouping Topics According to Bloom's Revised Taxonomy as LOTS and HOTS}

The 40 essay titles investigated were grouped into 12 topics as shown in Figure 4. From this figure, it becomes immediately evident that the Remembering cognitive objective was common to all topics examined over the 10 years. The next most-represented objective was Analyzing, (7 out of 12 topics), followed by the Understanding objective (4 out of 12 topics), and finally by the Evaluating objective (2 out of 12 ). 


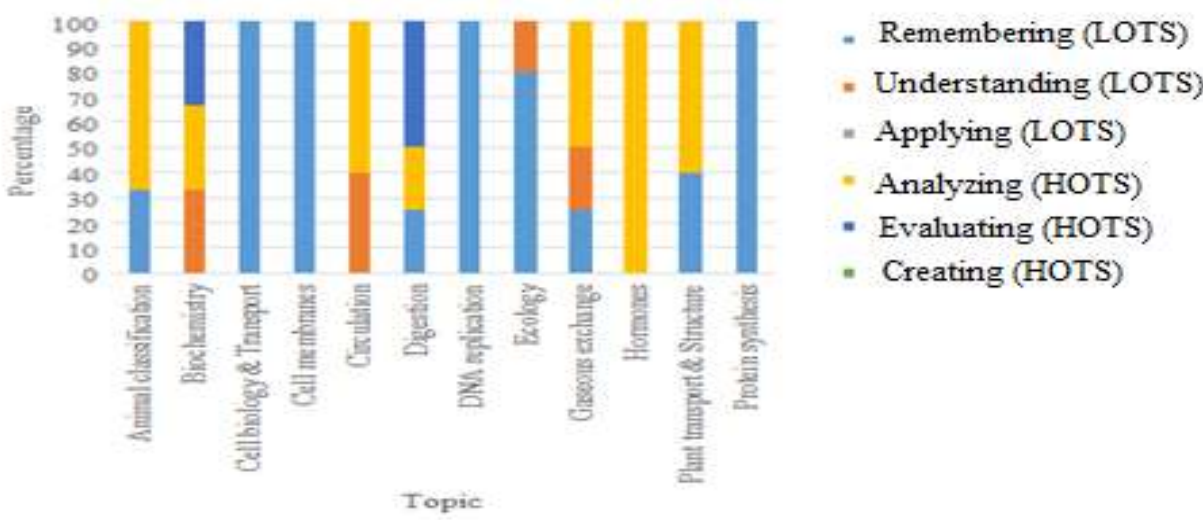

Figure 4: Percentage of Essay Questions Grouped by Cognitive Objective Based on Topic over the Period 2010-2019

(Source: Author's Own Illustrations)

The Evaluating cognitive objective was represented by two topics: Biochemistry and Digestion. The Biochemistry title: 'Polymer function is supported by its molecular structure. Discuss this statement with reference to a named: (i) structural polysaccharide, (ii) pigmented polypeptide in erythrocytes and (iii) polynucleotide stored in the nucleus of a eukaryotic cell' and the Digestion title: 'The human digestive system is adapted to carry out digestion and absorption efficiently. Discuss this statement relating to how structural features of the system are adapted to carry out these two functions. These two titles are thought-provoking and hence require HOTS. The topic Hormones was represented by a single title over the whole study period and was also regarded as requiring HOTS. The essay: 'Hormones can be classified as lipophilic (hydrophobic) or lipophobic (hydrophilic). Using a named example for each, compare and contrast the structure and mode of action of these hormones.' This essay was categorized as belonging to the Analyzing cognitive objective as the student was required to break up the material into its constituents to make its organizational structure comprehensive.

From Figure 4, it can be observed that $58 \%$ (7 out of 12) of examinable topics, involved HOTS questions (Analyzing and Evaluating objectives). It may be seen that three topics (Cell membranes, DNA replication, and Protein synthesis) comprised 100\% LOTS (Figure 5). It is widely acknowledged that writing HOTS questions is difficult (Palmer \& Devitt, 2007) and requires training. 


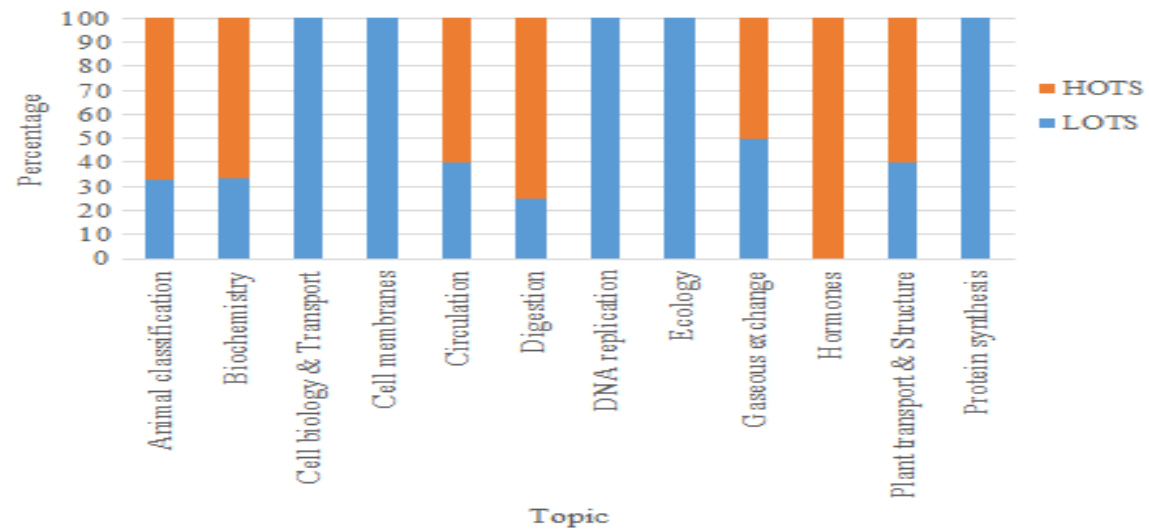

Figure 5: Percentage of LOTS and HOTS Essay Questions Classified by Topic over the Period 2010-2019

(Source: Author's Own Illustrations)

\section{Conclusions}

At the particular institution investigated, LOTS essay questions predominate in Advanced Level Biology end-of-year examinations. The largest amount of essay questions was categorized in the Remembering and Understanding cognitive objectives. Questions with such objectives were present in practically all topics investigated. If essays are to test HOTS, examiners are to be given proper instruction so that in each examination, essay titles are constructed to cover a wider range of cognitive objectives. However, it must be observed that irrespective of a large percentage of essay titles being classified as LOTS, does not automatically mean that they were easy.

Trustingly, this study sheds awareness on the cognitive level of essay questions, leading to an improvement for future examinations. This study revealed the cognitive objective of each essay title over ten years, which can be used as a database that gives examiners indications of which titles examine LOTS and which HOTS, thus they can formulate questions having a mixture of both. This makes examinations more effective.

\subsection{Research Limitations and Scope of Future Work}

Some limitations may be identified in this study. The first is that essays from only one post-secondary institution were investigated and hence results recorded here may not reflect those at the National level. It would also be interesting to investigate the essay titles that appear at other local post-secondary institutions. This limitation could act as a platform for future research where the cognitive level of essay questions from various institutions is compared to each other as well as to those in the National examination. Since only one type of question, the 
essay, was investigated, it does not reveal the overall cognitive level of the examination. This is thus another limitation, which although can be remedied by further research, was beyond the scope of this paper.

Another limitation is that the total number of questions analyzed was limited since a small number of titles, four, appear in each examination. A way to get around this could have been to extend the period, however, this would introduce another problem - that of repetition of titles. The number of topics investigated also imposes a limitation. Since the examination is taken after the end of the first year of tuition, the number of examinable topics is limited. This may be the reason for certain topics, such as Ecology, to be repeatedly examined; $21 \%$ of Ecology essay titles appeared over the period 2010-2019. The results of this study shed light on the importance of setting a database that paper-setters can consult to produce an examination paper that is not only intellectually challenging but also varied for topic choice.

\section{REFERENCES}

Anderson, L.W., Krathwohl, D.R., Airasian, P.W., Cruikshank, K.A., Mayer, R.E., Pintrich, P.R., Raths, J., \& Wittrock, M.C. (2001). A Taxonomy for Learning, Teaching, and Assessing: A revision of Bloom's Taxonomy of Educational Objectives. New York: Pearson, Allyn \& Bacon

Azzopardi, C., \& Azzopardi, M. (2020). Analysing Maltese Biology Examination Questions according to Cognitive Complexity. European Journal of Teaching and Education. 2. 3241.https://doi.org/10.33422/ejte.v2i4.524

Azzopardi, M., \& Azzopardi, C. (2021). Classification of Maltese biology examination questions using Bloom's Revised Taxonomy. Symposia Melitensia, 17, 107-122

Cullinane, A., \& Liston, D. (2016). Review of the Leaving Certificate biology examination papers (1999-2008) using Bloom's taxonomy - an investigation of the cognitive demands of the examination.Irish Educational Studies, 35:3, 249267https://doi.org/10.1080/03323315.2016.1192480

Edussuriya, D.H., Waduge, R.N., Lamawansa, M.D., \& Samaranayake, A.N., (2018). Evaluation of the cognitive level of essay questions of an undergraduate medical program in Sri 
Lanka, using bloom's taxonomy. Sri Lanka Journal of Medicine, 27(1), 310.https://doi.org/10.4038/sljm.v27i1.72

Kurdi, M. S. (2015). Essay type questions \& their improvements \& short answer questions. Medical Education Technology Workshop, At Kims, India. Retrieved from https://www.researchgate.net/publication/281026940 ESSAY TYPE QUESTIONS TH EIR_IMPROVEMENTS_SHORT_ANSWER_QUESTIONS

Matriculation Certificate Examinations Advanced Biology Syllabus 2019, MATSEC $\begin{array}{lllll}\text { Examinations } & \text { Board } & \text { University } & \text { (31pp). Retrieved }\end{array}$ fromhttps://www.um.edu.mt/_data/assets/pdf_file/0020/352460/AM05.pdf

Mercieca, L. (2014). Trends In MATSEC Advanced Level Biology From 1998 To 2011. Unpublished dissertation Presented to the Faculty of Education in Part Fulfilment of the Requirements for the Degree of Bachelor in Education (Honours) at the University of Malta (398pp)

Nippold, M. A., LaFavre, S., \&Shinham, K. (2020). How adolescents interpret the moral messages of fables: Examining the development of critical thinking. Journal of Speech, Language Hearing Research (Online),63(4),12121226.https://doi.org/10.1044/2019_JSLHR-19-00168

Palmer, E.J., \& Devitt, P.G. (2007). Assessment of higher order cognitive skills in undergraduate education: modified essay or multiple choice questions? Research paper.BMC Medical Education, 7: 49.https://doi.org/10.1186/1472-6920-7-49

Statistical Report (2020): Matriculation Certificate Examinations 81 pp. MATSEC Examinations Board, Universita' Ta' Malta

Supovitz, J. (2009). Can High-Stakes Testing Leverage Educational Improvement? Prospects from the Last Decade of Testing and Accountability Reform. Journal of Educational Change, 10 (Anniversary Issue): 211-227.https://doi.org/10.1007/s10833-009-9105-2 